Jurnal Ekonomi dan Bisnis, Vol. 8 No. 2 September 2021

$P$ - ISSN : 2503-4413

E - ISSN : 2654-5837, Hal $61-70$

\title{
ANALISIS PENGARUH BAURAN PEMASARAN HOLISTIK TERHADAP LOYALITAS NASABAH TABUNGAN PADA BANK $X$
}

Oleh :

Mohammad Fahmi Arkanuddin,

Program Studi Manajemen - STIE DR. KHEZ. Muttaqien

fahmi.arkanuddin@gmail.com

Indra Maulana,

Program Studi Manajemen - STIE DR. KHEZ. Muttaqien indra.maulana1177@gmail.com

\begin{tabular}{l}
\hline Article Info \\
\hline Article History : \\
Received 29 July - 2021 \\
Accepted 02 Sept - 2021 \\
Available Online 25 Sept - \\
2021
\end{tabular}

Keyword:

Banks, Holistic Marketing

Mix, Savings Customer

Loyalty, and SPSS

\begin{abstract}
This study uses a quantitative-descriptive approach, with SPSS 22 analysis tool to test the model. This study was conducted to analyze the significance of the influence of holistic marketing mix variables, namely product, price, promotion, place people, process, program and performance on customer loyalty savings. Holistic marketing mix variables have a significant effect on customer loyalty savings, namely: product, price, people and performance, while the variables that have no significant effect are: promotion, place, process and program. The coefficient of determination or $R$ is 0.955 , this indicates that the holistic marketing mix is able to affect customer loyalty savings by $95.50 \%$ of which $4.50 \%$ is influenced by other variables not examined. Banks can focus on 4 (four) significant variables by increasing the performance of product, price, people and performance variables, namely in terms of making strategies, business plans and work programs to increase savings customer loyalty, so as to increase benefits and profits for banks both for the time being. this time and in the future, meanwhile, banks can improve the performance of promotion, place, process and program, so that they can contribute positively to savings performance.
\end{abstract}

\section{PENDAHULUAN}

Bank merupakan lembaga intermediary, di mana bank menghimpun dana dari surplus unit dan menyalurkannya kepada pihak spending unit, sesuai dengan pengertian bank menurut UU Perbankan No.10 Tahun 1998,.Pasal 1 yaitu Bank adalah badan usaha yang menghimpun dana dari masyarakat dalam bentuk simpanan dan menyalurkannya kepada masyarakat dalam bentuk kredit dan/atau bentuk- bentuk lainnya dalam rangka meningkatkan taraf hidup rakyat banyak.

Persaingan antar bank sangat kompetitif dan tajam terutama di dalam memperebutkan dana nasabah dan jumlah nasabah atau jumlah rekening, khususnya low cost funding atau dana murah seperti giro dan tabungan. Setiap bank memiliki strategi masing-masing di dalam memperebutkan nasabah (volume dana murah dan jumlah rekening), untuk hal tersebut bank menerapkan strategi implementasi 
bauran pemasaran holistik atau dikenal sebagai bauran pemasaran baru, yang tidak hanya meliputi $4 P$ 's Marketing Mix, yaitu product, price, place and promotion, tetapi ada tambahan 4 (empat) variabel baru yaitu: people, process, program dan performance, sehingga jumlah variabel pemasaran holistik atau bauran pemasaran baru ada 8 (delapan) variabel, yaitu: product, price, place and promotion, people, process, program dan performance. Pelaksanaan strategi bauran pemasaran holistik ini diasumsikan dapat mempengaruhi loyalitas nasabah tabungan pada bank. Implementasi bauran pemasaran holistik sebagai variabel yang dapat mempengaruhi loyalitas nasabah, sehingga bank perlu menganalisis variabel bauran pemasaran holistik yang signifikan yang mempengaruhi loyalitas nasabah, hal ini perlu dilakukan agar strategi yang diterapkan dapat berhasil dalam meningkatkan jumlah rekening dari existing customers.

Loyalitas nasabah saat ini menjadi suatu permasalahan konseptual, mengingat saat ini nasabah dapat dengan mudah pindah dari satu bank ke satu bank lainnya, karena faktor sensitivitas terhadap rate atau suku bunga dan fasilitas layanan bank. Loyalitas nasabah existing yang dimiliki harus dijaga dengan baik oleh bank, agar bisnis dapat tumbuh, karena apabila nasabah tidak loyal dan mudah pindah bank lain, maka akuisisi nasabah baru yang dilakukan oleh bank akan sia-sia, karena hanya akan menutupi dari nasabah existing yang tidak loyal yang pindah ke bank lain, sehingga tidak menambah jumlah nasabah tabungan baru. Permasalahan loyalitas nasabah ini, terutama loyalitas nasabah tabungan, karena nasabah tabungan dapat dengan mudah tertarik ke bank lain hanya masalah iming-iming hadiah undian, hadiah langsung, point reward dan rate khusus (bunga spesial) bahkan hal yang kecil sekalipun seperti layanan yang kurang memuaskan dari petugas bank seperti customer service, teller bahkan marketing funding akan sangat mudah mendorong nasabah pindah ke bank lain.

Loyalitas nasabah akan berhasil, apabila existing customers yang dimiliki bank tidak berkurang jumlahnya, sementara jumlah nasabah baru semakin bertambah. Bank perlu mengetahui berapa banyak jumlah nasabah dan jumlah rekening yang dimiliki, sehingga dapat dimaintain dengan baik, agar nasabah dan jumlah rekening yang ada tidak berkurang dan harus selalu meningkat secara konsisten.

Penciptaan loyalitas nasabah berdasarkan pada tujuan agar nasabah selalu bertransaksi secara terus menerus dan berulang dengan bank serta menambah rekening baru. Pencapaian atas jumlah nasabah dan jumlah rekening tabungan yang meningkat harus dipertahankan melalui implementasi program loyalitas dan retensi, sementara itu proses menumbuhkan pertambahan jumlah rekening baru dapat diciptakan dari existing customers, selain mengakuisi rekening baru, sehingga hasil akhir dari strategi customer loyalty tercapai, yaitu mempertahankan jumlah nasabah yang dimiliki dan meningkatkan jumlah rekening dari jumlah nasabah yang dimiliku atau existing customers. Strategi loyalitas nasabah tabungan dapat dirumuskan melalui beberapa program marketing, agar nasabah yang ada tetap loyal dan tidak berkurang serta nasabah baru makin bertambang, melalui penerapan program marketing one stop banking services sesuai dengan profil dan kebutuhan nasabahnya.

\section{KAJIAN PUSTAKA DAN PENGEMBANGAN HIPOTESIS}

Pemasaran holistik (Kotler and Keller, 2012 : p.41) menyatakan bahwa konsep pemasaran holistik didasarkan pada pengembangan, desain, dan implementasi program pemasaran, proses, dan aktivitas yang menggambarkan hubungan saling ketergantungan. Pemasaran holistik menjelaskan bahwa semua hal penting dalam pemasaran dan perspektif yang luas dan terpadu sering diperlukan.

Bauran Pemasaran (Kotler and Armstrong, 1997:p.48) mendefiniskan bahwa bauran pemasaran adalah perangkat alat pemasaran taktis yang dapat dikendalikan, produk, harga, distribusi, dan promosi yang dipadukan oleh perusahaan untuk menghasilkan respons yang diinginkan dalam pasar sasaran. Philip Kotler (1997) menyatakan bahwa bauran pemasaran merupakan seperangkat alat pemasaran yang perusahaan gunakan untuk mengejar sasaran pasar. Alma (2005:205) mendefinisikan bauran pemasaran adalah strategi mengkombinasikan kegiatan-kegiatan marketing, agar tercipta kombinasi maksimal sehingga memunculkan hasil paling memuaskan. Stanton mendefinisikan bauran pemasaran adalah bauran pemasaran adalah istilah yang digunakan untuk menggambarkan suatu kombinasi dari 4 (empat) elemen yang diinternalisasikan ke dalam sistem marketing inti perusahaan. Keempat elemen tersebut adalah penawaran produk, struktur harga, kegiatan promosi dan sistem distribusi. Bauran pemasaran holistik terdiri atas 8 (delapan) elemen, yaitu: Product, Price, Place, Promotion, People, Process, Program dan Performance.

Loyalitas menurut Gremler dan Brown (dalam Ali Hasan, 2008:p83) menyatakan bahwa loyalitas adalah pelanggan yang tidak hanya membeli ulang 
suatu barang dan jasa, tetapi juga mempunyai komitmen dan sikap yang positif terhadap perusahaan jasa, misalnya dengan merekomendasikan orang lain untuk membeli. Engel, Blackwell, Miniard (dalam Ali Hasan, 2008 : 84) memberikan pendapat tentang loyalitas adalah kebiasaan perilaku pengulangan pembelian, keterkaitan dan keterlibatan yang tinggi pada pilihannya, dan bercirikan dengan pencarian informasi eksternal dan evaluasi alternatif. Olson (dalam Trisno Mushanto, 2004 128) menyampaikan buah pikirannya bahwa yang dimaksud loyalitas adalah dorongan perilaku untuk melakukan pembelian secara berulang-ulang dan untuk membangun kesetiaan pelanggan terhadap suatu produk maupun jasa yang dihasilkan oleh badan usaha tersebut yang membutuhkan waktu yang lama melalui suatu proses pembelian yang terjadi secara berulang-ulang. Griffin (1995) menyatakan bahwa tingkat loyalitas, yaitu: (i) Suspects; (ii) Prospects; (iii) Disqualified Prospects; (iv) First Time Customers; (v) Repeat Custumers; (vi) Clients; (vii) Advocates dan (viii) Partners. Swastha dan Handoko (dalam Joko Riyadi 2004: p. 83), ada 5 (lima) faktor utama yang mempengaruhi loyalitas konsumen, yaitu: (i) Kualitas Produk ; (ii) Kualitas Pelayanan; (iii) Emosional; (iv) Harga dan (v) Biaya.. Tahapan Perkembangan Loyalitas menurut Brown: (i) Loyalitas Kognitif yaitu loyalitasnya hanya didasarkan basis informasi yang memaksa menunjuk pada suatu merk terhadap merk lainnya dan menekankan pada aspek kognisi (pengharapan) saja; (ii) Loyalitas Afektif, yaitu loyalitas didasarkan pada sikap dan perilaku (behaviour); (iii) Loyalitas Konatif, yaitu dimensi Konatif (niat melakukan) dipengaruhi oleh perubahan-perubahan afektif terhadap merk. Konasi menunjukkan suatu niat atau komitmen untuk melakukan sesuatu ke sebuah tujuan tertentu. Riset Crosby dan Taylor (dalam Ali Hasan, 2008:88) menggunakan model runtutan psikologis: keyakinan sikap niat yang memperlihatkan komitmen (niat) melakukan. Afektif hanya menunjukkan kecenderungan motivasional, sedangkan komitmen melakukan menunjukkan suatu keinginan untuk menjalankan tindakan. Keinginan untuk membeli ulang atau menjadi loyal itu hanya merupakan tindakan yang diantisipasi tetapi belum terlaksana. Breckler dan Greenwald, Foxall dan Goldsmith, Bagozzi, Baumgartner dan Yi, (dalam Ali Hasan, 2008:88) menyatakan bahwa umumnya dalam kontrol tindakan, niat yang diikuti oleh motivasi, merupakan kondisi yang mengarah pada kesiapan bertindak dan keinginan untuk mengatasi hambatan untuk mencapai sesuatu dan penyelesaian hambatan.
Ini menunjukkan loyalitas itu dapat menjadi kenyataan melalui runtutan loyalitas kognitif, kemudian loyalitas afektif dan loyalitas konatif dan akhirnya sebagai loyalitas tindakan (loyalitas yang dibarengi dengan komitmen dan tindakan).

\section{METODE PENELITIAN}

Desain Penelitian menggunakan metode kuantitatif yang digambarkan secara deskriptif. Jumlah sampel yang diambil sebanyak 96 sampel, secara non probability sampling dengan metode purposive sampling, pada nasabah tabungan di kantor cabang bank seluruh Indonesia. Alat Analisis Menggunakan software SPSS untuk mengolah data hasil penelitian dari penyebaran kuesioner kepada seluruh nasabah tabungan yang memiliki rekening tabungan bank. Pengujian dilakukan untuk beberapa uji hasil, yaitu: (i) Uji Validitas; (ii) Uji Reliabilitas; (iii) Uji Asumsi Klasik yang terdiri atas uji normalitas, uji multikolineritas, uji heterokedastisitas; (iv) Uji Hipotesis, yang terdiri atas uji $\mathrm{T}$ (parsial), uji $\mathrm{F}$ (simultan) dan uji $\mathrm{R}^{2}$ ( $\mathrm{R}$ square) dan Analisis Multiple Regression

Tabel 1 Dimensi/Indikator- Pemasaran Holistik

\begin{tabular}{|c|c|c|c|}
\hline Variabel & Dimensi/Indikator & Kode & Sumber \\
\hline \multirow{4}{*}{ Peoples } & SDM Pelayanan & $\mathrm{PEO}_{1}$ & \multirow{4}{*}{$\begin{array}{l}\text { Philip } \\
\text { Kotler } \\
(2002)\end{array}$} \\
\hline & Pelanggan & $\mathrm{PEO}_{2}$ & \\
\hline & SDM Pemasaran & $\mathrm{PEO}_{3}$ & \\
\hline & Pimpinan Pemasaran & $\mathrm{PEO}_{4}$ & \\
\hline Variabel & Dimensi/Indikator & Kode & Sumber \\
\hline \multirow{4}{*}{ Process } & $\begin{array}{l}\text { Keinginan, Kebutuhan } \\
\text { dan Permintaan }\end{array}$ & $\mathrm{PRS}_{1}$ & \multirow{4}{*}{$\begin{array}{l}\text { Philip } \\
\text { Kotler } \\
(2002)\end{array}$} \\
\hline & $\begin{array}{l}\text { Segmentasi, Sasaran } \\
\text { Pasar dan Posisi }\end{array}$ & $\mathrm{PRS}_{2}$ & \\
\hline & $\begin{array}{ll}\text { Saluran } & \text { Distribusi } \\
\text { Pemasaran } & \end{array}$ & $\mathrm{PRS}_{3}$ & \\
\hline & Nilai dan Kepuasan & $\mathrm{PRS}_{4}$ & \\
\hline Variabel & Dimensi/Indikator & Kode & Sumber \\
\hline \multirow{4}{*}{ Program } & Produk & $\mathrm{PRG}_{1}$ & \multirow{4}{*}{$\begin{array}{l}\text { Philip } \\
\text { Kotler } \\
(2002)\end{array}$} \\
\hline & Harga & $\mathrm{PRG}_{2}$ & \\
\hline & Tempat/Lokasi & $\mathrm{PRG}_{3}$ & \\
\hline & Promosi & $\mathrm{PRG}_{4}$ & \\
\hline Variabel & Dimensi/Indikator & Kode & Sumber \\
\hline \multirow{4}{*}{ Product } & Tahan Lama & $\mathrm{PRD}_{1}$ & \multirow{4}{*}{$\begin{array}{c}\text { Fandy } \\
\text { Tjiptono } \\
(2015: 156)\end{array}$} \\
\hline & Karakteristik atau Fitur & $\mathrm{PRD}_{2}$ & \\
\hline & Kehandalan & $\mathrm{PRD}_{3}$ & \\
\hline & Kesan Kualitas & $\mathrm{PRD}_{4}$ & \\
\hline Variabel & Dimensi/Indikator & Kode & Sumber \\
\hline \multirow{4}{*}{ Price } & Keterjangkauan & $\mathrm{PRI}_{1}$ & \multirow{4}{*}{$\begin{array}{c}\text { Fandy } \\
\text { Tjiptono } \\
(2015: 156)\end{array}$} \\
\hline & $\begin{array}{l}\text { Kesesuaian harga } \\
\text { dengan kualitas produk }\end{array}$ & $\mathrm{PRI}_{2}$ & \\
\hline & Daya Saing Harga & $\mathrm{PRI}_{3}$ & \\
\hline & $\begin{array}{ll}\text { Kesesuaian } & \text { Harga } \\
\text { dengan Manfaat }\end{array}$ & $\mathrm{PRI}_{4}$ & \\
\hline
\end{tabular}




\begin{tabular}{|c|c|c|c|}
\hline Variabel & Dimensi/Indikator & Kode & Sumber \\
\hline Variabel & Dimensi/Indikator & Kode & Sumber \\
\hline \multirow{4}{*}{ Place } & Lokasi & $\mathrm{PLA}_{1}$ & \multirow{4}{*}{$\begin{array}{l}\text { (Mischitelli, } \\
\text { 2000) }\end{array}$} \\
\hline & Halaman Parkir & $\mathrm{PLA}_{2}$ & \\
\hline & $\begin{array}{l}\text { Kemudahan } \\
\text { dijangkau/diakses }\end{array}$ & $\mathrm{PLA}_{3}$ & \\
\hline & Visibilitas & $\mathrm{PLA}_{4}$ & \\
\hline Variabel & Dimensi/Indikator & Kode & Sumber \\
\hline \multirow{4}{*}{ Promotion } & $\begin{array}{l}\text { Frekuensi (seberapa } \\
\text { sering iklan dilihat dan } \\
\text { dibaca), }\end{array}$ & $\mathrm{PRO}_{1}$ & \multirow{4}{*}{$\begin{array}{l}\text { Wells } \\
(2010)\end{array}$} \\
\hline & $\begin{array}{l}\text { Intensitas } \text { (seberapa } \\
\text { jauh khalayak mengerti } \\
\text { pesan iklan) }\end{array}$ & $\mathrm{PRO}_{2}$ & \\
\hline & $\begin{array}{l}\text { Durasi (seberapa lama } \\
\text { khalayak } \\
\text { memperhatikan iklan) }\end{array}$ & $\mathrm{PRO}_{3}$ & \\
\hline & Pesan iklan & $\mathrm{PRO}_{4}$ & \\
\hline Variabel & Dimensi/Indikator & Kode & Sumber \\
\hline \multirow{4}{*}{ Performance } & Keuangan & $\mathrm{PER}_{1}$ & \multirow{4}{*}{$\begin{array}{l}\text { Philip } \\
\text { Kotler } \\
(2002)\end{array}$} \\
\hline & Non Keuangan & $\mathrm{PER}_{2}$ & \\
\hline & Tanggung Jawab Sosial & $\mathrm{PER}_{3}$ & \\
\hline & $\begin{array}{l}\text { Pengusaha/Wiraswasta } \\
\text { Sosial }\end{array}$ & $\mathrm{PER}_{4}$ & \\
\hline Variabel & Dimensi/Indikator & Kode & Sumber \\
\hline \multirow{4}{*}{ Loyalty } & $\begin{array}{l}\text { Melakukan pembelian } \\
\text { ulang secara teratur }\end{array}$ & $\mathrm{LOY}_{1}$ & \multirow{4}{*}{$\begin{array}{l}\text { Jill Griffin } \\
\text { (Dalam } \\
\text { Hurriyati, } \\
\text { 2010;p.130) }\end{array}$} \\
\hline & $\begin{array}{l}\text { Melakukan pembelian } \\
\text { di luar lini produk/jasa }\end{array}$ & $\mathrm{LOY}_{2}$ & \\
\hline & $\begin{array}{l}\text { Merekomendasikan } \\
\text { Produk }\end{array}$ & $\mathrm{LOY}_{3}$ & \\
\hline & $\begin{array}{l}\text { Menunjukkan } \\
\text { kekebalan dari daya } \\
\text { tarikan produk sejenis } \\
\text { dari pesaing }\end{array}$ & $\mathrm{LOY}_{4}$ & \\
\hline
\end{tabular}

\section{HASIL DAN PEMBAHASAN}

Uji Hipotesis terdiri atas Uji T (Parsial), Uji F dan Uji $\mathrm{R}^{2}$, untuk detail dan hasil uji dapat dilihat pada Tabel 7.7. di bawah ini

Tabel 2 Uji T (Parsial) Coefficients ${ }^{\mathrm{a}}$

\begin{tabular}{|l|c|r|r|r|r|r|r|}
\hline \multirow{3}{*}{ Model } & \multicolumn{2}{|c|}{$\begin{array}{c}\text { Unstandardized } \\
\text { Coefficients }\end{array}$} & $\begin{array}{c}\text { Std. } \\
\text { Coeff }\end{array}$ & \multirow{2}{*}{$\mathrm{t}$} & \multirow{2}{*}{ Sig. } & \multicolumn{2}{c|}{$\begin{array}{c}\text { Colinearity } \\
\text { Statistics }\end{array}$} \\
\cline { 2 - 5 } \cline { 3 - 5 } & \multicolumn{1}{c|}{$\mathrm{B}$} & $\begin{array}{c}\text { Std } \\
\text { Error }\end{array}$ & Beta & & & Tolerance & VIF \\
\hline (Constant) & -1.173 & .699 & & -626 & $\mathbf{. 1 0 8}$ & & \\
\hline Product & .313 & .051 & .344 & 6.109 & $\mathbf{. 0 0 0}$ & .321 & 3.118 \\
\hline Price & .265 & .041 & .296 & 6.440 & $\mathbf{. 0 0 0}$ & .481 & 2.078 \\
\hline Promo & .015 & .038 & .015 & .383 & $\mathbf{. 7 0 3}$ & .645 & 1.550 \\
\hline Place & -.052 & .034 & -.063 & - & $\mathbf{. 1 2 8}$ & .601 & 1.663 \\
\hline People & .239 & .049 & .239 & 4.923 & $\mathbf{. 0 0 0}$ & .431 & 2.318 \\
\hline Process & -.020 & .050 & -.024 & -.402 & $\mathbf{. 6 8 9}$ & .288 & 3.473 \\
\hline Program & .081 & .048 & .077 & 1.675 & $\mathbf{. 0 9 7}$ & .481 & 2.081 \\
\hline Perform & .226 & .053 & .243 & 4.263 & $\mathbf{. 0 0 0}$ & .314 & 3.187 \\
\hline
\end{tabular}

Nilai Sig dibandingkan dengan taraf signifikansinya

\begin{tabular}{|c|c|c|c|}
\hline Variabel & Sig. & $\begin{array}{c}\text { Taraf } \\
\text { Sig. }\end{array}$ & Keterangan \\
\hline Product & $\mathbf{. 0 0 0}$ & $\mathbf{< 0 , 0 5}$ & Berpengaruh Signifikan \\
\hline
\end{tabular}

\begin{tabular}{|l|c|c|lc|}
\hline \multicolumn{1}{|c|}{ Variabel } & Sig. & $\begin{array}{c}\text { Taraf } \\
\text { Sig. }\end{array}$ & \multicolumn{2}{|c|}{ Keterangan } \\
\hline Price & $\mathbf{. 0 0 0}$ & $<\mathbf{0 , 0 5}$ & \multicolumn{2}{|c|}{ Berpengaruh Signifikan } \\
\hline Promotion & $\mathbf{. 7 0 3}$ & $<0,05$ & $\begin{array}{l}\text { Berpengaruh } \\
\text { Signifikan }\end{array}$ & Tidak \\
\hline Place & $\mathbf{. 1 2 8}$ & $<0,05$ & $\begin{array}{l}\text { Berpengaruh } \\
\text { Signifikan }\end{array}$ & Tidak \\
\hline People & $\mathbf{. 0 0 0}$ & $<\mathbf{0 , 0 5}$ & Berpengaruh Signifikan \\
\hline Process & $\mathbf{. 6 8 9}$ & $<0,05$ & $\begin{array}{l}\text { Berpengaruh } \\
\text { Signifikan }\end{array}$ & Tidak \\
\hline Program & $\mathbf{. 0 9 7}$ & $<0,05$ & $\begin{array}{l}\text { Berpengaruh } \\
\text { Signifikan }\end{array}$ & Tidak \\
\hline Performance & $\mathbf{. 0 0 0}$ & $<\mathbf{0 , 0 5}$ & $\begin{array}{l}\text { Berpengaruh } \\
\text { Signifikan }\end{array}$ & Sangat \\
\hline
\end{tabular}

Uji F (Simultan) dilakukan untuk menguji pengaruh secara simultan dari seluruh variable independent terhadap variable dependent, hasil uji $\mathrm{F}$ (Simultan) dengan bantuan program komputer SPSS 22, dapat diihat pada Tabel 7.8. di bawah ini

Tabel 3 Hasil Uji F (Simultan)

\section{ANNOVA $^{\mathrm{a}}$}

\begin{tabular}{|c|l|c|c|c|c|c|}
\hline \multirow{2}{*}{ Model } & & $\begin{array}{c}\text { Sum Of } \\
\text { Squares }\end{array}$ & df & $\begin{array}{c}\text { Mean } \\
\text { Square }\end{array}$ & F & Sig. \\
\hline \multirow{3}{*}{1} & Regression & 453.582 & 8 & 56.698 & \multirow{2}{*}{11.998} & \multirow{2}{*}{$.000^{\mathrm{b}}$} \\
\cline { 2 - 5 } & Residual & 44.043 & 87 & .506 & & \\
\cline { 2 - 5 } & Total & 497.625 & 95 & .506 & & \\
\hline
\end{tabular}

a. Dependent Variable : Decision

b. Predictors: (Constant), performance, promotion, price, program, people, product, process.

Nilai Sig. di atas $\mathbf{. 0 0 0}{ }^{\mathbf{b}}<\mathbf{0 , 0 5}$, maka terdapat pengaruh yang signifikan dari seluruh variable tersebut secara simultan terhadap Loyalitas Nasabah.

Uji $\mathrm{R}^{2}$ (Koefisien Determinasi) mengukur seberapa besar pengaruh variabel independen secara keseluruhan terhadap naik turunnya variasi nilai variabel dependen untuk uji $\mathrm{R}^{2}$ menggunakan menggunakan program komputer SPSS 22 dapat dilihat pata Tabel 7.9/ di bawah ini.

Tabel 4 Hasil Uji R ${ }^{2}$

Model Summary ${ }^{\mathrm{b}}$

\begin{tabular}{|c|c|c|c|c|}
\hline Model & $\mathrm{R}$ & $\begin{array}{c}\mathrm{R} \\
\text { Square }\end{array}$ & $\begin{array}{c}\text { Adjusted } \boldsymbol{R} \\
\text { Square }\end{array}$ & $\begin{array}{c}\text { Std.Error Of } \\
\text { the Estimate }\end{array}$ \\
\hline 1 & $.955^{\mathrm{a}}$ & .911 & .903 & .712 \\
\hline
\end{tabular}

a. Predictors: (Constant), Performance,

Promotion, Price, Place, Program, People,

Product, Process.

b. Dependent Variabel "Loyalitas Nasabah

Dari Tabel diatas, nilai koefisien determinasi (adjusted $R$ square) sebesar $\mathbf{0 , 9 0 3}$, artinya pengaruh variabel independen (X) terhadap dependen (Y) sebesar $\mathbf{9 0 . 3 0 \%}$. Hal ini berarti loyalitas nasabah (Y) dipengaruhi variabel independen (X) sebesar $\mathbf{9 0 . 3 0 \%}$ dan sisanya 9.70 \% dipengaruhi oleh variabel lain yang tidak diteliti. 
Tabel 5 Hasil Uji Model Summary

Model Summary ${ }^{\mathrm{b}}$

\begin{tabular}{|c|c|c|c|c|c|}
\hline Model & $\mathrm{R}$ & $\begin{array}{c}\mathrm{R} \\
\text { Square }\end{array}$ & $\begin{array}{c}\text { Adjusted } \\
\text { R Square }\end{array}$ & $\begin{array}{c}\text { Std.Error } \\
\text { Of the } \\
\text { estimate }\end{array}$ & $\begin{array}{c}\text { Durbin- } \\
\text { Watson }\end{array}$ \\
\hline 1 & $.955^{\mathrm{a}}$ & .911 & .903 & .712 & 1.633 \\
\hline
\end{tabular}

a. Predictors: (Constant), Performance,

Promotion, Price, Place, Program,

People, Product, Process.

b. Dependent Variable: Loyalitas_Nasabah

Tabel 6 Hasil Uji ANOVA

ANOVA ${ }^{\mathrm{a}}$

\begin{tabular}{|r|l|r|r|r|r|r|}
\hline \multicolumn{2}{|c|}{ Model } & $\begin{array}{c}\text { Sum Of } \\
\text { Squares }\end{array}$ & df & $\begin{array}{c}\text { Mean } \\
\text { Square }\end{array}$ & F & Sig. \\
\hline 1 & Regression & 453.582 & 8 & 56.698 & 111.998 & $.000^{\mathrm{b}}$ \\
\hline & Residual & 44.043 & 87 & .506 & & \\
\hline & Total & 497.625 & 95 & & & \\
\hline
\end{tabular}

a. Dependent Variable : Loyalitas_Nasabah

b. Predictors: (Constant), Performance, Promotion, Price, Place, Program, People, Product, Process.

Tabel 7. Hasil Uji Coefficients Coefficients $^{\mathbf{a}}$

\begin{tabular}{|c|c|c|c|c|c|c|c|}
\hline \multirow{2}{*}{ Model } & \multicolumn{2}{|c|}{$\begin{array}{c}\text { Unstandardized } \\
\text { Coefficients }\end{array}$} & \multirow{2}{*}{$\begin{array}{c}\begin{array}{c}\text { Std. } \\
\text { Coeff }\end{array} \\
\text { Beta }\end{array}$} & \multirow{2}{*}{$\mathrm{t}$} & \multirow{2}{*}{ Sig. } & \multicolumn{2}{|c|}{$\begin{array}{c}\text { Colinearity } \\
\text { Statistics }\end{array}$} \\
\hline & B & $\begin{array}{c}\text { Std } \\
\text { Error }\end{array}$ & & & & Tolerance & VIF \\
\hline (Constant) & -1.173 & .699 & & $1626^{-}$ & .108 & & \\
\hline Product & .313 & .051 & .344 & 6.109 & .000 & .321 & 3.118 \\
\hline $\begin{array}{l}\text { Price } \\
\end{array}$ & .265 & .041 & .296 & 6.440 & .000 & .481 & 2.078 \\
\hline Promo & .015 & .038 & .015 & .383 & .703 & .645 & 1.550 \\
\hline Place & -.052 & .034 & -.063 & 1.535 & .128 & .601 & 1.663 \\
\hline People & .239 & .049 & .239 & 4.923 & .000 & .431 & 2.318 \\
\hline Process & -.020 & .050 & -.024 & -.402 & .689 & .288 & 3.473 \\
\hline Program & .081 & .048 & .077 & 1.675 & .097 & .481 & 2.081 \\
\hline Perform & .226 & .053 & .243 & 4.263 & .000 & .314 & 3.187 \\
\hline
\end{tabular}

Hasil uji analisis Multiple Regression, maka dapat dijelaskan sebagai berikut:

$\mathbf{b}_{\mathbf{0}} \mathbf{- 1 , 1 3 7} \quad$ Konstanta yang bernilai negative (-) berapapun nilai (-), maka diabaikan saja , artinya tidak mempengaruhi terhadap Loyalitas Nasabah.

b1 $0,313 \quad$ Koefisien variabel product sebesar $\mathbf{0 , 3 1 3}$ berarti setiap kenaikan nilai 1 pada variable product akan meningkatkan sebesar $\mathbf{0 , 3 1 3}$ pada variable loyalitas nasabah dengan asumsi variabel yang lainnya konstan.

$\mathbf{b}_{\mathbf{2}} \mathbf{0 , 2 6 5}$ Koefisien variabel price sebesar $\mathbf{0 , 2 6 5}$ berarti setiap kenaikan nilai 1 pada variable price maka akan meningkatkan sebesar $\mathbf{0 , 2 6 5}$ pada variable loyalitas nasabah dengan asumsi variable yang lainnya konstan.

$\mathbf{b}_{3} \mathbf{0 , 0 1 5}$ Koefisien variabel promotion sebesar 0,015 berarti setiap kenaikan nilai 1 pada variabel promotion, maka tidak meningkatkan pada variabel loyalitas nasabah dengan asumsi variable yang lainnya konstan. (tidak signifikan, Nilai Sig. > 0.05)

$\mathbf{b}_{\mathbf{4}} \mathbf{- 0 , 0 5 2}$ Koefisien variabel place sebesar $\mathbf{0 , 0 5 2}$ berarti setiap kenaikan nilai 1 pada variable place, maka akan tidak meningkatkan pada variable loyalitas nasabah dengan asumsi variable yang lainnya konstan. (tidak signifikan)

b5 0,239 Koefisien variabel people sebesar 0,239 berarti setiap kenaikan nilai 1 pada variable people maka akan meningkatkan sebesar 0,239 pada variable loyalitas nasabah dengan asumsi variable yang lainnya konstan.

$\mathbf{b}_{6}-\mathbf{0 , 0 2 0}$ Koefisien variabel process sebesar $\mathbf{0 , 0 2 0}$ berarti setiap kenaikan nilai 1 pada variable process, maka tidak meningkatkan pada variable loyalitas nasabah dengan asumsi variable yang lainnya konstan. (tidak signifikan)

b $_{7} \mathbf{0 , 0 8 1}$ Koefisien variabel program sebesar 0,081 berarti setiap kenaikan nilai 1 pada variable program, maka tidak meningkatkan pada variable loyalitas nasabah dengan asumsi variable yang lainnya konstan. (tidak signifikan)

b8 0,226 Koefisien variabel performance sebesar $\mathbf{0 , 2 2 6}$ berarti setiap kenaikan nilai 1 pada variable performance maka akan meningkatkan sebesar $\mathbf{0 , 2 2 6}$ pada variable loyalitas nasabah dengan asumsi variable yang lainnya konstan.

Berdasarkan temuan dalam penelitian, alasan dan pertimbangan, suatu variable dikatakan memiliki pengaruh signifikan dan tidak memiliki pengaruh signifikan yaitu sebagai berikut:

Variabel berpengaruh signifikan, yaitu:

Product

Nasabah merasa produk tabungan memberikan suatu benefit yang lebih baik dibandingkan penawaran lain 
serta memiliki paket produk customized, sehingga sesuai kebutuhan. Untuk hal tersebut, nasabah selalu mereferensikan kepada pihak lain dan memanfaatkan seluruh transaksi keuangannya di tabungan payroll

Price Nasabah merasa biaya/tariff tabungan jauh lebih kompetitif dibandingkan penawaran lainnya, sehingga tetap loyal dan setia bertransaksi meskipun dari bank lain melakukan pendekatan atau berencana untuk melakukan take over rekening tabungan payroll.

People Nasabah merasa nyaman dan aman ditangani oleh relationship manager yang memahami kebutuhan keuangan. Pendekatan secara personal menyebabkan nasabah dihargai dan dibutuhkan oleh Bank, sehingga kedua belah pihak dalam melakukan transaksi saling menguntungkan. Penanganan dari RM dilakukan secara holistic dan memberikan layanan one stop banking services, membuat nasabah menjadi betah dan tidak berkeinginan untuk tertarik dengan bank lain.

Performance Bank dalam memberikan kualitas pelayanan tidak membeda-bedakan antara nasabah yang satu dengan nasabah lainnya dan semuanya diperlakukan sama, sehingga seluruh kebutuhan layanan jasa telah dipenuhi oleh bank dengan baik selain itu juga delivery produk dan jasa dilakukan secara cepat, tepat waktu dan pada saat waktu yang tepat pula.

Variabel berpengaruh tidak signifikan, yaitu:

Promotion Bank tidak melakukan promosi secara rutin baik below the line maupun above the line promotion, dan hanya sebatas referensi atau mouth to mouth (dari mulut ke mulut), sehingga tidak semua nasabah yang ada tahu tentang produk tabungan payroll.

Place Nasabah yang ada saat ini sudah merasa nyaman dengan fasilitas jemput bola dari bank, sehingga nasabah tidak perlu datang ke kantor cabang yang ada untuk melakukan transaksi pembukaan rekening, sehingga dimanapun lokasi kantor tidak berpengaruh terhadap transaksi yang akan dilakukan secara rutin. Selain itu juga channel distribution lainnya sangat membantu nasabah , seperti pemanfaatan fasilitas internet banking, mobile banking dan sms banking.

Process Kegiatan proses operasional yang dilakukan setiap kantor cabang konvensional terhadap transaksi nasabah tidak berpengaruh signifikan karena proses transaksi secara cepat sudah digantikan secara proses elektronik melalui pemanfaatan internet banking, mobil banking dan sms banking.

Program Kebutuhan nasabah lebih kepada kemudahan untuk melakukan transaksi kapanpun dan dimanapun, sehingga meskipun ada programprogram pemasaran yang menarik tidak semua nasabah yang ada aware dan tertarik, mengingat belum tentu sesuai dengan kebutuhan nasabah saat ini.

Variabel-variabel memiliki pengaruh signifikan tersebut dikembangkan digali lebih jauh untuk membuat strategi dan rencana kerja di masa mendatang agar loyalitas nasabah lebih meningkat dan memberikan kontribusi dan benefit lebih bagi kinerja produk tabungan. Variabel Product mempengaruhi signifikan terhadap loyalitas nasabah tabungan sebesar 0.313. Variabel Price mempengaruhi signifikan terhadap loyalitas nasabah tabungan sebesar 0.265. Variabel People mempengaruhi signifikan terhadap loyalitas nasabah tabungan sebesar 0.239. Variabel Performance mempengaruhi signifikan terhadap loyalitas nasabah tabungan sebesar $\mathbf{0 . 2 2 6}$.

Berdasarkan hasil penelitian dengan menggunakan pendekatan kuantitatif dengan alat analisis SPSS, maka penelitian ini berimplikasi terhadap pentingnya mengembangkan strategi terhadap 4 (empat) variabel utama yang memiliki pengaruh signifikan terhadap loyalitas nasabah tabungan, dengan fokus terhadap 4 (empat) variabel tersebut, maka diharapkan bank dapat meningkatkan jumlah dana dan jumlah rekening tabungan secara 
signifikan selain strategi memperbaiki 4 (empat)

variabel yang tidak signifikan pengaruhnya.

Implikasi lain dari hasil penelitian ini adalah

bank harus membuat analisis SWOT terhadap 4 (empat) variabel signifikan tersebut, agar bank dapat bersaing dengan bank lain dalam meningkatkan kinerja produk tabungan di masa mendatang, selain itu juga bank harus fokus dengan penigkatan kompetensi SDM marketing, karena pada dasarnya nasabah perusahaan berhubungan bisnis dengan bank tidak melihat bank-nya tetapi melihat SDM marketingnya, sehingga kekuatan SDM marketing akan menjadi ujung tombak pemasaran produk tabungan di kemudian hari, di mana peningkatan kompetensi SDM dapat dilakukan dengan memberikan pelatihan secara rutin.

Penelitian dilakukan untuk mengkonfirmasi teori bauran pemasaran holistik, sehingga ke depan dapat dikembangkan penelitian terkait dengan 4 (empat) variabel yang memiliki pengaruh signifikan, sehingga dapat memberikan suatu pemahaman komprehensif terkait 4 (empat) variabel Product, Price, People dan Performance, terutama untuk variabel people yang akan menjadi kekuatan suatu bank dalam melakukan pemasaran.

\section{KESIMPULAN DAN SARAN}

Berdasarkan hasil penelitian yang telah dilakukan dan didukung dengan teori yang relevan serta metode analisis data yang digunakan, maka dapat diperoleh beberapa kesimpulan bahwa hasil dari perhitungan multiple regression dengan menggunakan metode enter, terdapat 4 (empat) variable yang signifikan yang mempengaruhi loyalitas nasabah tabungan, yaitu: (i) Variabel Product; (ii) Variabel Price; (iii) Variabel People dan (iv) Variabel Performance (Service Quality). Strategi pemasaran yang dijalankan bank dengan melakukan analisis SWOT terlebih dahulu dan berikutnya membuat dan menetapkan strategi pemasaran yang fokus pada 4 (empat) variable signifikan, di mana untuk penetapan strategi pemasaran dilakukan melalui penetapan STP, yaitu: Segmentation (Segmentasi Pasar); Targeting (Sasaran Pasar); Positioning (Penempatan Posisi). Masing-masing variable, seperti variabel Product ditentukan strategi pemasarannya dengan menentukan STP Product, STP Price, STP People dan STP Performance. Prospek produk tabungan di masa mendatang sangat bagus dan prospektif, bila dilakukan penajaman dan pendalaman terhadap STP maisng-masing variable signifikan, sehingga dapat dikembangkan secara kreatif dan inovatif STP yang ada, agar dapat mendukung terhadap keunggulan daya saing produk, produk menjadi lebih menarik dan produk menjadi kompetitif, hal yang sama dilakukan untuk variable Price, People dan Performance.

Potensi peluang lainnya yang dapat menjadikan produk tabungan dapat lebih prospektif adalah besarnya peluang pasar untuk pemasaran produk ini, yaitu: (i) Peluang makro, antara lain: (i.1.) Jumlah perusahaan UMKM di Indonesia sangat besar, dan berpotensi untuk menjadi nasabah tabungan: (i.2.) Jumlah pemilik rekening di Bank masih belum terlalu besar di bandingkan jumlah populasi Indonesia; (i.3.) Jumlah kebutuhan finansial keluarga di Indonesia dari tahun ke tahun semakin meningkat; (i.4.) Komposisi demografi Indonesia merupakan demografi usia muda dan usia produktif (pekerja), sehingga di masa mendatang akan membutuhkan investasi, simpanan serta pinjaman bank; (ii) Peluang mikro , dari internal bank, antara lain; (ii.1.) Sebagian besar debitur bank, masih belum melakukan kerja sama untuk pembukaan rekening tabungan, sehingga dapat didorong untuk melakukan pembukaan rekening tabungan; (ii.2.) Sebagian besar nasabah deposan (giro dan deposito) dengan status badan usaha/perusahaan belum seluruhnya memiliki rekening tabungan; (ii.3.) Pertumbuhan jumlah rekening simpanan (tabungan) meningkat signifikan dari tahun ke tahun sehingga merupakan market potensial untuk ditawarkan tabungan khususnya untuk nasabah perusahaan; (ii.4.) Customer base bank yang cukup besar akan menjadi potensi pasar untuk produk tabungan

\section{REFERENSI}

Agustinus. 2003. Dasar - Dasar Pemasaran. Edisi Kesembilan. Jilid 2. Jakarta: Indeks.

Alma, Buchari. 2004. Manajemen Pemasaran dan Pemasaran Jasa. Cetakan Keenam. Bandung: Alfabeta.

Andhiyan, Nanang. 2012. Pengaruh Marketing Mix Terhadap Loyalitas Konsumen.

Anoraga, Pandji. 2005. Pengantar Bisnis. Jakarta: Rineka Cipta.

Arikunto, Suharsimi. 2002. Prosedur Penelitian. Jakarta: Rineka cipta.

Assael, Henry. 1998. Consumer Behavior and Marketing Action. Ohio: SouthWestern Collage Publishing. 
Assauri, Sofyan. 2004. Manajemen Pemasaran. Jakarta: Raja Grafindo.

Barners, James G. 2001. Secrets of Customer Relationship Management: It's All About How You Make Them Feel. New York: McGraw-Hill.

Basu Swastha, D.H. 2006. Manajemen Pemasaran Modern. Edisi kedua.Yogyakarta: Liberty Offset.

Basu Swastha dan Irawan. 2003. Manajemen Pemasaran Modern. Edisi kedua, Cetakan Kesebelas. Yogyakarta: Liberty Offset.

Bloemer, Josee, Ko de Ruyter, Pascal Peters. 1998. Investigating Drivers of Bank Loyalty: The Complex Relationship between Image, Service Quality, and Satisfaction". International Journal of Bank Marketing, Vol 16. Issue 7 Date.

Dalimunthe, G. P. 2011. Pengaruh Kinerja Bauran Pemasaran Jasa terhadap Loyalitas Pelanggan (Studi Kasus di Braga Music School Bandung. Jurnal InSearch Universitas Informatika dan Bisnis Indonesia) 4: 1-9.

Dolan. 1991. Strategic Marketing Management. Boston, Masschussetts: Harvard Business School Publications, P.88.

Durkheim, Emile. 1933. The Division of Labour in Society. Translated by George Simpson. London: The Tree Press of Glencoe ColliesMac Millan Limited.

Fandy Tjiptono. 1997. Strategi Pemasaran. Yogyakarta: Andi.

Fauziyah, Siti Nurul. Marketing Mix Terhadap Loyalitas Pelanggan Enceng Gondok Di Daerah Groyok Kabupaten Lamongan. Jurnal. Universitas Negeri Surabaya.

Freddy Rangkuti. 2000. Measuring Customer Satisfaction. Jakarta: PT. Gramedia.

Gage, Susan M. 2006. Strategi Pelayanan Pelanggan. Yogyakarta: Argo.

Ghozali, Imam. 2005. Aplikasi Analisis Multivariate dengan Program SPSS. Jakarta: Gramedia Pustaka Utama.

Griffin, J. 2009. Customer Loyalty: How to Earn It, How to Keep It. Jakarta: Gelora Aksara Pratama. Hal 7, 41.

Ghozali, I. 2011. Aplikasi Analisis Multivariate Dengan Program IBM SPSS 19. Semarang. Universitas Diponegoro.Hal 48, 53, 97, 98, 139.

Ghozali, Imam. 2005. Aplikasi Analisis Multivariate dengan Program SPSS. Jakarta. Gramedia Pustaka Utama.
Gujarati, N.D. 2003. Basic Econometrics. 4th ed. New York: McGraw-Hill Companies, Inc.

Hasan, F. D. 2012. Pengaruh Bauran Pemasaran Jasa Terhadap Loyalitas Nasabah pada PT Bank Rakyat Indonesia (PERSERO) Tbk, Cabang Achmad Yani Makassar. Skripsi. Jurusan Manajemen. Fakultas Ekonomi dan Bisnis. Universitas Hasanuddin. Makassar. Hal 69.

Hurriyati, Ratih. 2005. Bauran Pemasaran dan Loyalitas Konsumen. Bandung: Alfabeta

Husein, Umar. 2005. Metode Penelitian Untuk Skripsi dan Tesis Bisnis. Jakarta: Raja Grafindo Persada.

Kartajaya, Hermawan dan Syakir Sula, Muhammad. 2006. Syariah Marketing. Bandung: Mizan.

Kotler, Philip dan Amstrong, Gary. 2008. Prinsip Prinsip Pemasaran, Edisi Dua Belas, Jilid I. Jakarta: Erlangga.

Kotler, Philip dan Keller. 2007. Manajemen Pemasaran Jilid 1, Edisi keduabelas. Jakarta: Indeks. Kotler, Philip. 1995. Manajemen pemasaran, Analisa, Perencanaan, Implementasi dan Pengendalian, Jilid I, edisi kedelapan. Jakarta: Salemba Empat.

Kotler, Philip. 2000. Manajemen Pemasaran. Edisi Milenium. Jakarta: Prenhalindo.

Kotler, Philip. 2000. Marketing Management. Nem Jersey: Prentice Hall International Inc.

Kotler, Philip. 2000. Manajemen Pemasaran Edisi Milenium Jilid 1 \& 2. Jakarta: Prenhalindo.

Kotler, Philip. 2002. Manajemen Pemasaran. Jilid 2. Jakarta. Bumi Aksara.

Kotler, Philip. 2004. Manajemen Pemasaran Jilid I, Edisi kesembilan, Jakarta: Dadi Kaguna Abadi Erlangga.

Kotler, Philip. 2004. Manajemen Pemasaran. Jilid I, Edisi kesebelas. Jakarta. Indeks.

Kotler, Philip. 2005. Manajemen Pemasaran. Jilid II, Edisi Kesebelas.Jakarta: Indeks.

Kotler, Phillip. 2005. Manajemen Pemasaran Edisi Milenium. Jilid 1. Jakarta: Indeks.

Kotler, Philip dan Amstrong. 2001. Dasar Dasar Pemasaran. Edisi 9. Jakarta: Indeks.

Kotler, Philip dan Amstrong, Gary 2001. Prinsip Prinsip Pemasaran, Edisi Delapan, Jilid I. Jakarta: Erlangga.

Kutner, M.H., C.J. Nachtsheim., dan J. Neter. 2004. Applied Linear Regression Models. 4th edition. New York: McGraw-Hill Companies, Inc.

Larasati, V., Suryaputra, R dan Amelia. 2013. Analisis Faktor-faktor yang Mempengaruhi Loyalitas Pelanggan Coffee Toffee Jatim 
Expo di Surabaya. Jurnal Gema Aktualita 3 (2): 7-17.

Lovelock, Christoper H. \& Laurer Wreight. 1999. Principles of Service Marketing and Management. New Jersey: Prentice Hall.

Lovelock, Christopher H dan Wright Lauren K. 2005. Manajemen Pemasaran Jasa. Jakarta: Indeks.

Lupiyoadi, Rambat dan A. Hamdani. 2006. Manajemen Pemasaran Jasa., Jakarta: Salemba Empat.

Lupiyoadi, Rambat. 2004. Manajemen Pemasaran jasa. Edisi Pertama Jakarta : Salemba Empat.

Malhotra, Naresh K. 2005. Riset Pemasaran Edisi Keempat Jilid 1. Jakarta: Indeks.

Nasir Ph.D, Moh. 2003. Manajemen Pemasaran Jasa. Jakarta: Ghalia Indonesia.

Oliver, Richard. 1999. Whence Consumer Loyalty?. Journal Of Marketing. Vol. 63 (special Issue 1999), 33-44.

Probosuci, Kustania dan Deoranto, Panji dan Santoso, Imam. 2014. Analisis Pengaruh Bauran Pemasaran Terhadap Loyalitas Pelanggan (Studi Kasus: Restoran Jepang Saboten Shokudo, Malang. Jurnal. Universitas Brawijaya.

Purwanto, Iwan .2008. Manajemen Strategi, Bandung: Yrama Widya.

Putri, A. D. 2010. Analisis Kepuasan dan Loyalitas Konsumen Restoran Pecel Madiun Pondok Sekararum serta Implikasinya terhadap Strategi Bauran Pemasaran. Skripsi. Bogor: Departemen Agribisnis, Fakultas Ekonomi dan Manajemen, IPB. Hal. 76.

Putriana, P. E. 2010. Analisis Kepuasan dan Loyalitas Konsumen Midori Japanese Restaurant Cabang K. H Wahid Hasyim Jakarta Pusat. Skripsi. Bogor: Departemen Agribisnis. Fakultas Ekonomi dan Manajemen IPB.

Rangkuti, F. 1997. Analisis SWOT Teknik Membedah Kasus Bisnis, Jakarta: Gramedia Pustaka.

Rangkuti, Freddy. 2006. Analisis Swot Teknik Membedah Kasus Bisnis, Jakarta: Gramedia Pustaka Utama.

Rangkuti, Freddy. 1997. Riset Pemasaran. Jakarta: Gramedia Pustaka Utama, Jakarta.

Ratih, Hurriyati. 2005. Bauran Pemasaran dan Loyalitas Konsumen. Bandung: Alfabeta:

Rismiati CE dan Suratno B. 2001. Pemasaran Barang dan Jasa. Yogyakarta: Kanisius.

Rosen, Emanuel. 2000. The Anatomy of Buzz: how to create word-of-mouth marketing. New York: Doubleday.
Saladin, I. 2005. Manajemen Pemasaran, Analisis, Perencanaan, Pelaksanaan dan Pengendalian. Bandung: Lindakarya.

Selang, C. A. D. 2013. Bauran Pe masaran (Marketing Mix) pengaruhnya Terhadap Loyalitas Konsumen Pada Fresh Mart Bahu Mall Manado. Jurnal EMBA 1 (3) : 71-80.

Setiawardi, Aripin dan Ramdhani, M.Ali dan Ikhwana, Andri. 2013. Pengaruh Bauran Pemasaran Jasa Terhadap Loyalitas Pelanggan di Taman Air Panas Derajat Pass. Jurnal Kalibrasi. ISSN: 23027320 Vol. 11 No. 12013.

Shimp, T. A. 2008. Periklanan Promosi Aspek Tambahan Komunikasi Pemasaran Terpadu. Jakarta: Erlangga, Hal 15.

Simamora, B. 2005. Analisis Multivariat Pemasaran. Jakarta: Gramedia Pustaka Utama.

Sinamora, Bilson. 2004. Riset Pemasaran. Jakarta: Gramedia Pustaka Utama.

Sugiyono. 2008. Metode Penelitian Kuantitatif Kualitatif dan R\& D. Bandung: Alfabeta.

Sugiyono. 2007. Metode Penelitian Bisnis. Bandung: Alfabeta.

Stanton, William. 1996. Prinsip-prinsip Pemasaran Jilid Kedua Edisi Ketujuh. Jakarta.

Stewart, Grant. 2005. Sukses Manajemen Penjualan. Jakarta: Erlangga.

Stoner, Freeman and Gilbert Jr. 1995. Management, 6th ed. Englewood Cliffs, N.J: Prentice-Hall Internation, Inc.

Tandjung, Jenu Widjaja. 2004. Marketing Management Pendekatan Pada Nilai Pelanggan. Jakarta: Bayumedia.

Tjiptono, Fandy Dan Greorius, Chandra. 2008. Pemasaran Strategic, Edisi 1 Yogyakarta: Andi Ofset. Tjiptono, Fandy. 2007. Strategi Bisnis Pemasaran. Andi: Yogyakarta.

Umar, H. 2003. Strategic Management In Action. Jakarta: Gramedia Pustaka Utama.

Umar, Drs. Husein. 1997. Metodologi Penelitian Aplikasi Dalam Pemasaran. Penerbit : Gramedia Pustaka Utama.

Wahudi, Agustinus Sri. 2003. Manajemen Strategi. Jakarta : Binarupa Aksara.

Yonaldi, Sepris. 2011. Analisis Pengaruh Variabel Bauran Pemasaran (Marketing Mix) Terhadap Loyalitas Konsumen Produk Minuman Teh Botol Frestea (Studi Kasus Mahasiswa Universitas Andalas Padang ), Jurnal Manajemen dan Kewirausahaan, Volume 2, Nomor 1, Januari 2011, ISSN: $2086-5031$. 
Zeithaml, Valerie, A, Mary, Jo, Bitner. 2000. Service Marketing, Integrating Customer Focus Across The Firm, second edition,
International edition, Singapore: Prentice Hall. 